\title{
No effect of anti-TNF- $\alpha$ treatment on serum IL-17 in patients with rheumatoid arthritis
}

\author{
DOROTA SIKORSKA ${ }^{l}$, RAFAŁ RUTKOWSKI ${ }^{2}$, JOANNA ŁUCZAK², WŁODZIMIERZ SAMBORSKI ${ }^{1}$, \\ JANUSZ WITOWSKI
}

${ }^{1}$ Department of Rheumatology and Rehabilitation, Poznan University of Medical Sciences, Poznan, Poland

${ }^{2}$ Department of Pathophysiology, Poznan University of Medical Sciences, Poznan, Poland

\begin{abstract}
Introduction: Interleukin 17 (IL-17) and CC-chemokine ligand 20 (CCL20) are increasingly implicated in the pathogenesis of rheumatoid arthritis (RA). A correlation has been reported to exist between serum levels of IL-17 and CCL2O and the disease activity. However, such an effect has not been universally demonstrated. The aim of the present study was to investigate if serum levels of IL-17 and/ or CCL2O reflect the disease activity and response to anti-TNF- $\alpha$ therapy in patients with $R A$.

Material and methods: Twenty-two RA patients qualified to receive anti-TNF- $\alpha$ treatment were prospectively assessed before and after 12 weeks of therapy. Serum concentrations of IL-17 and CCL2O were measured with high-sensitivity immunoassays. Disease activity was assessed by the 28-joint disease activity score (DAS28).

Results: Twelve weeks of therapy resulted in a satisfactory therapeutic response in the majority (91\%) of patients (reflected both by clinical and standard biochemical criteria). However, serum concentrations of IL-17 and CCL2O did not change significantly over the course of therapy Moreover, they did not correlate with the disease activity, patient characteristics, and their response to therapy.

Conclusions: Serum levels of IL-17 and CCL2O do not reflect changes in the clinical and biochemical status that occur in patients undergoing anti-TNF- $\alpha$ treatment for RA. The lack of such an association indicates that IL-17 signalling is not affected by anti-TNF- $\alpha$ therapy and is thus not critically involved in the disease pathogenesis.
\end{abstract}

Key words: rheumatoid arthritis, interleukin-17, chemokine CCL20, anti-TNF- $\alpha$ treatment.

(Centr Eur J Immunol 2018; 43 (3): 270-275)

\section{Introduction}

Tumour necrosis factor $\alpha$ (TNF- $\alpha$ ) plays a major role in the progression of joint destruction and proliferation of synoviocytes in rheumatoid arthritis (RA) [1]. Therapies neutralising TNF- $\alpha$ have greatly improved the treatment outcomes in RA [2]. Unfortunately, some RA patients do not respond to anti-TNF- $\alpha$ treatment, and in some patients positive responses cannot be maintained, suggesting that there are alternative drivers of RA pathogenesis [3]. Binding of antibodies to transmembrane TNF- $\alpha$ on target cells seems to be crucial for inducing complement-dependent cytotoxicity, antibody-dependent cellular cytotoxicity, and reverse signalling. However, these processes alone do not fully explain the mechanism of responses to anti-TNF- $\alpha$ therapy [4].

Curiously, treatment with TNF- $\alpha$ inhibitors does not significantly affect circulating TNF- $\alpha$ levels [5] and does not modulate the expression of TNF- $\alpha$ in the synovial tissue [6]. Therefore, there may exist alternative drivers of
RA pathogenesis, which are affected by TNF- $\alpha$ inhibitors through as yet unidentified mechanisms [4].

The discovery that interleukin-17 (IL-17) is involved in autoimmune disease has created a new concept of the RA pathogenesis of RA [1]. Animal studies have shown there exists an association between IL-17 signalling and joint inflammation [7, 8]. IL-17 is derived largely from Th17 lymphocytes that differentiate from naive CD4 ${ }^{+}$ $\mathrm{T}$ cells in response to a particular combination of inflammatory cytokines. It has been demonstrated that IL-23 is essential for Th17 differentiation [9], acting together with IL-6, IL-1 $\beta$, IL-21, and TGF- $\beta$ [10]. Interestingly, TNF- $\alpha$ does not seem to be directly involved in this process [11]. In addition to IL-17, activated Th17 cells produce several proinflammatory cytokines and chemokines, including CC-chemokine ligand 20 (CCL20), which acts as a chemoattractant for Th17 cells. Thus, an increased production of IL-17 and CCL20 may result in a positive feedback loop leading to self-perpetuating chronic inflammation [9].

Correspondence: Dorota Sikorska, MD, PhD, Department of Rheumatology and Rehabilitation, Poznan University of Medical Sciences, 135/147 28 Czerwca 1956 St., 61-545 Poznan, Poland, e-mail: dorota_s8@wp.pl

Submitted: 12.10.2017; Accepted: 14.11.2017 
The exact role of IL-17 in RA is not fully understood [9]; it has been suggested that the mechanisms driving inflammation in RA could be different in different patients $[12,13]$. A correlation between serum levels of IL-17 (and of related molecules IL-23 and CCL20) and the disease activity has been observed in some studies [14-17] but not in others $[18,19]$. Moreover, it is unclear whether and how IL-17 impacts the effectiveness of anti-TNF- $\alpha$ treatment. Such an effect is possible because IL-17 has been demonstrated in many models to synergise with TNF- $\alpha$ to amplify the production of pro-inflammatory cytokines, including CCL20 [17]. Some studies have reported serum IL-17 and CCL20 clearly decreasing after anti-TNF- $\alpha$ treatment [17]. Other studies did not detect such an effect $[18,19]$ or found an increase in serum IL-17, even in patients with clinical improvement following the treatment [20].

Interestingly, the blockade of IL-17 signalling in RA does not always result in a desired clinical effect [21]. A recent meta-analysis has established that brodalumab, an IL-17R-antagonist, was not as effective as a placebo in RA [22]. Similarly, secukinumab, an anti-IL17 antibody, offered no-to-little improvement in RA. It has been suggested that the role of IL-17 in RA may depend on the stage of the disease [9]. Synovial fluid in early RA contains significantly elevated levels of IL-17 when compared with the synovial fluid from patients with long-lasting disease [23].

The aim of the present study was to investigate if serum levels of IL-17, CCL20, and/or IL-23 reflect the disease activity and response to anti-TNF- $\alpha$ therapy in patients with RA.

\section{Material and methods}

\section{Patients}

The study was performed prospectively on 22 consecutive Caucasian RA patients, qualified to initiate antiTNF- $\alpha$ treatment, according to American-European Consensus Group classification criteria [24]. The patients were evaluated before and after 12 weeks of therapy. The study was approved by the Poznan University of Medical Sciences Bioethics Committee (No. 1067/15), and all patients gave their informed consent.

\section{Disease activity}

Disease activity was assessed by the 28 -joint disease activity score (DAS28) [25]. It is calculated from the number of tender (TEN28) and swollen (SW28) joints, erythrocyte sedimentation rate (ESR), and the disease assessment by the patient (VAS), according to the formula: DAS $28=$ $0.56 \sqrt{ }($ TEN28) $+0.28 \sqrt{ }($ SW28 $)+0.70 \mathrm{Ln}($ ESR $)+0.014$ (VAS) [25]. The therapeutic response was evaluated after 12 weeks of therapy according to the European League Against Rheumatism (EULAR) response criteria [26].

\section{Laboratory analysis}

Samples of serum were collected by routine methods at the time of clinical examination in a fasting state. Serum was aliquoted and stored at $-70^{\circ} \mathrm{C}$ until assayed in batch. Serum concentrations of IL-17, CCL20, and IL-23 were measured with specific immunoassays (R\&D Systems, USA), as per manufacturer's instructions. Estimated detection levels were $0.01 \mathrm{pg} / \mathrm{ml}$ and $0.47 \mathrm{pg} / \mathrm{ml}$, and $16.3 \mathrm{pg} / \mathrm{ml}$ for IL-17, CCL20, and IL-23, respectively. Values below the detection limit were assigned a value of zero. All other laboratory tests were performed routinely by the hospital central laboratory.

\section{Statistical analysis}

Statistical analyses were performed with Statistica 10.0 software (StatSoft Polska, Krakow, Poland). Normality of the data distribution was tested with the Shapiro-Wilk's test. The data are presented as medians and interquartile ranges or means and standard deviations or percentage, as appropriate. The Wilcoxon test was used to compare parameters before and after treatment. Differences between unpaired data were analysed with the Mann-Whitney test. Correlation between variables was analysed with the Spearman's rank correlation coefficient. The differences were considered significant at $p<0.05$.

\section{Results}

Twenty-two patients with RA qualified to receive anti-TNF- $\alpha$ treatment were enrolled and analysed. All patients had previously been treated with (at least) two synthetic disease-modifying anti-rheumatic drugs (methotrexate, leflunomide, sulfasalazine, or cyclosporine) with no satisfactory effects. All patients had an active disease (DAS-28 > 5.1) and received anti-TNF- $\alpha$ treatment according to standard protocols. Eleven patients $(50 \%)$ received simultaneously methotrexate (the remaining patients did not tolerate methotrexate). Corticosteroids ( $\leq 5 \mathrm{mg}$ prednisone/ day) and non-steroid anti-inflammatory drugs (NSAIDs) were allowed but were given at stable doses for at least four weeks before and during anti-TNF- $\alpha$ therapy. Full clinical and demographic patient characteristics at baseline are presented in Table 1.

Twelve weeks of biologic treatment resulted in a significant improvement in the majority of the patients, with only two patients (9\%) identified as EULAR non-responders. The favourable response to therapy was reflected both by clinical and standard biochemical criteria (Table 2).

Serum concentrations of IL-17A and CCL20 did not change significantly over the course of therapy ([median and IQR] IL-17: 0.00 [0.00-3.31] vs. 0.17 [0.00-4.45] pg/ $\mathrm{ml}$ and CCL20: 22.0 [17.0-26.0] vs. 22.5 [19.0-31.0] pg/ml) (Figs. 1, 2). Serum IL-23 levels were below the detection limit both before and after the treatment. 
Also, the pattern of changes in serum IL-17 and CCL20 over the course of therapy showed no correlation with changes in standard inflammatory parameters (leukocytes, CRP and ESR) and disease activity (DAS28, SW28, TEN28, VAS). These patterns did not seem to be different

Table 1. Patients' baseline characteristics

\begin{tabular}{|c|c|}
\hline \multicolumn{2}{|c|}{ Demographic and clinical features } \\
\hline Age (years) & $52.8 \pm 12.4$ \\
\hline $\operatorname{Men}(\%)$ & $3(14)$ \\
\hline Disease duration (years) & $10.3 \pm 6.7$ \\
\hline Rheumatoid factor, presence (\%) & $18(82)$ \\
\hline BMI $\left(\mathrm{kg} / \mathrm{m}^{2}\right)$ & $24.2 \pm 4.5$ \\
\hline Current smoking (\%) & $4(18)$ \\
\hline Other diseases (\%) & $\begin{array}{l}\text { Diabetes: } 1 \text { (4) } \\
\text { Hypertension: } 8 \text { (36) }\end{array}$ \\
\hline \multicolumn{2}{|c|}{ Treatment } \\
\hline Prednisone $(<5 \mathrm{mg} / 24 \mathrm{~h})(\%)$ & $12(54)$ \\
\hline NSAIDS (\%) & $17(77)$ \\
\hline Methotrexate (\%) & $11(50)$ \\
\hline Anti-TNF- $\alpha$ treatment $(\%)$ & $\begin{array}{l}\text { adalimumab: } 5(23) \\
\text { certolizumab: } 9(41) \\
\text { etanercept: } 2(9) \\
\text { golimumab: } 2(9) \\
\text { infliximab: } 4(18)\end{array}$ \\
\hline
\end{tabular}

in patients who did not respond to therapy. There was also no apparent association between the magnitude of serum IL-17 or CCL20 and the type of anti-TNF- $\alpha$ agent used, or between the simultaneous treatment with corticosteroids and NSAIDs).

Table 2. Selected parameters before and after treatment

\begin{tabular}{|c|c|c|c|}
\hline & $\begin{array}{l}\text { Before treatment } \\
\quad(n=22)\end{array}$ & $\begin{array}{l}\text { After 12-weeks of treatment } \\
\qquad(n=22)\end{array}$ & $\begin{array}{c}p \text {-value } \\
\text { (Wilcoxon test) }\end{array}$ \\
\hline DAS28 (ESR) & $5.34(5.18-6.08)$ & $3.56(3.15-3.99)$ & $<0.001$ \\
\hline TEN28 & $10.0(8.0-12.0)$ & $2.0(1.0-3.0)$ & $<0.001$ \\
\hline SW28 & $6.0(4.0-9.0)$ & $1.5(0.0-4.0)$ & $<0.001$ \\
\hline VAS (mm) & $70(60-82)$ & $41(30-50)$ & $<0.001$ \\
\hline $\operatorname{ESR}(\mathrm{mm} / \mathrm{h})$ & $22(10-30)$ & $15(8-25)$ & 0.012 \\
\hline $\mathrm{CRP}(\mathrm{mg} / \mathrm{l})$ & $6.80(2.30-15.80)$ & $2.15(0.10-5.50)$ & 0.021 \\
\hline Leukocytes $\left(10^{3} / \mu \mathrm{l}\right)$ & $8.8(7.2-9.9)$ & $7.8(6.6-9.6)$ & 0.022 \\
\hline Neutrophils $\left(10^{3} / \mu \mathrm{l}\right)$ & $5.4(3.6-7.1)$ & $4.7(3.3-5.8)$ & 0.006 \\
\hline Lymphocytes $\left(10^{3} / \mu 1\right)$ & $2.0(1.6-2.6)$ & $2.2(1.7-3.1)$ & 0.079 \\
\hline Neutrophil-to-lymphocyte ratio & $2.3(1.8-3.8)$ & $1.7(1.3-2.7)$ & 0.024 \\
\hline Erythrocytes $\left(10^{6} / \mu \mathrm{l}\right)$ & $4.5(4.3-4.7)$ & $4.5(4.3-4.6)$ & 0.357 \\
\hline Haemoglobin (g/dl) & $12.5(11.9-13.6)$ & $12.3(12.1-13.5)$ & 0.765 \\
\hline Platelets $\left(10^{3} / \mu \mathrm{l}\right)$ & 299 (268-319) & $272(259-309)$ & 0.044 \\
\hline
\end{tabular}

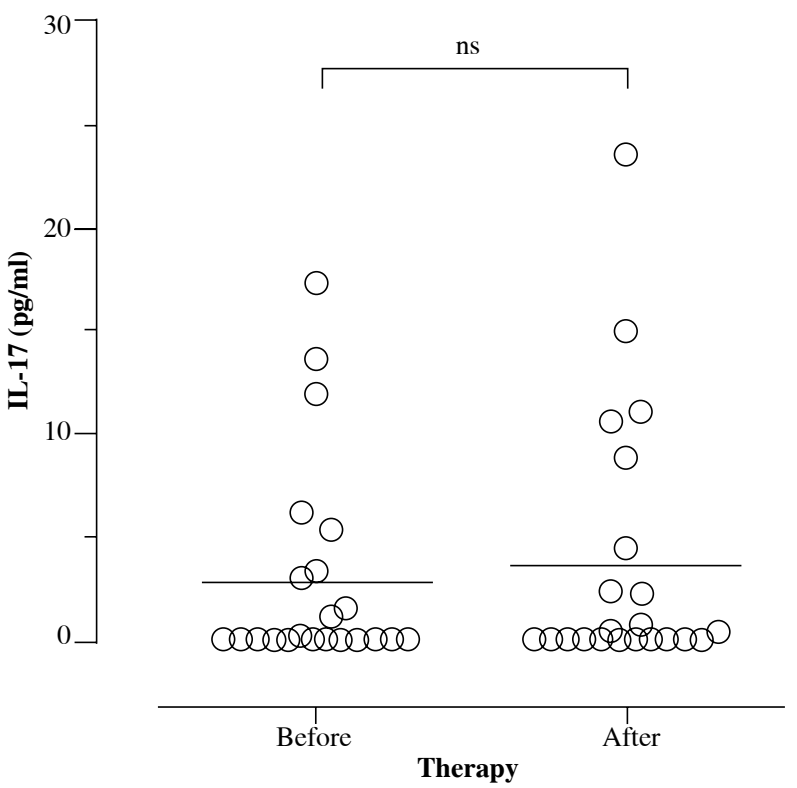

Fig. 1. Individual changes in serum IL-17 A during anti-TNF- $\alpha$ therapy in rheumatoid arthritis patients 


\section{Discussion}

The main observation of the present study is that the mean serum concentrations of IL-17 and CCL20 did not change significantly over the course of anti-TNF- $\alpha$ therapy and did not parallel changes in the clinical disease activity and standard biochemical parameters.

Such associations were absent also in other studies $[18,19]$ and included no correlation between serum IL-17 radiologic features of RA and no changes following the treatment $[18,19]$. However, other studies detected a correlation between serum IL-17 and CCL20 and the disease activity and the response to biologic therapy [14-17].

We also tried to evaluate whether baseline serum levels of IL-17 and CCL20 could be prognostic markers for predicting therapeutic response to biologic therapy in RA. Our data show that the measurement of serum IL-17 and CCL20 does not provide additional information that would help to predict the response to treatment more accurately. Since, however, only two patients did not respond to treatment, it is difficult to draw final conclusions in this respect. Earlier studies did not identify IL-17 as a predictor of successful response to therapy with either anti TNF- $\alpha$ [27] or anti-IL-6R [27, 28]. On the other hand, Yue et al. demonstrated that high baseline levels of circulating Th17 cells were negative predictors of the effect of anti-TNF- $\alpha$ therapy [29]. And accordingly, high baseline levels of IL-17were also shown to predict poor therapeutic response to anti-TNF treatment [13]. Here, we detect no predictive value of IL-17 or (for the first time) Th17-attracting chemokine CCL20.

The lack of any apparent associations of IL-17 in our study could be related the long course of the disease in the patient group analysed. Although Th17 cells in peripheral blood are relatively more frequent in patients with early RA [29], such an observation was absent in later stages of RA [30]. In addition, Th17 cells are found only rarely in joints of patients with long-lasting inflammation [9]. Also, IL-17 in the synovial fluid appears to be elevated in early - but not in late-stage RA [23]. Moreover, the frequency of Th17 cells and serum IL-17 levels did not correlate with the disease activity (DAS28) in long-lasting RA [18, 30].

Animal studies suggested the existence of both IL-23/ IL-17-dependent and IL-23/IL-17-independent stages of arthritis [31] and showed a limited time window for antiIL-17 treatment to be effective in chronic arthritis [9].

It has also been suggested that different members of the IL-17 cytokine family play roles at different stages of RA. In this respect IL-17(A) is thought to be an inducer of inflammation, while IL-17F is implicated in chronic inflammation [32, 33]. Accordingly, the blockade of IL-17A in long-lasting RA has been shown to be of less clinical benefit than in early disease [34].

Our results might have been affected also by naturally low levels of IL-17 in serum [32]. If fact, serum IL-17

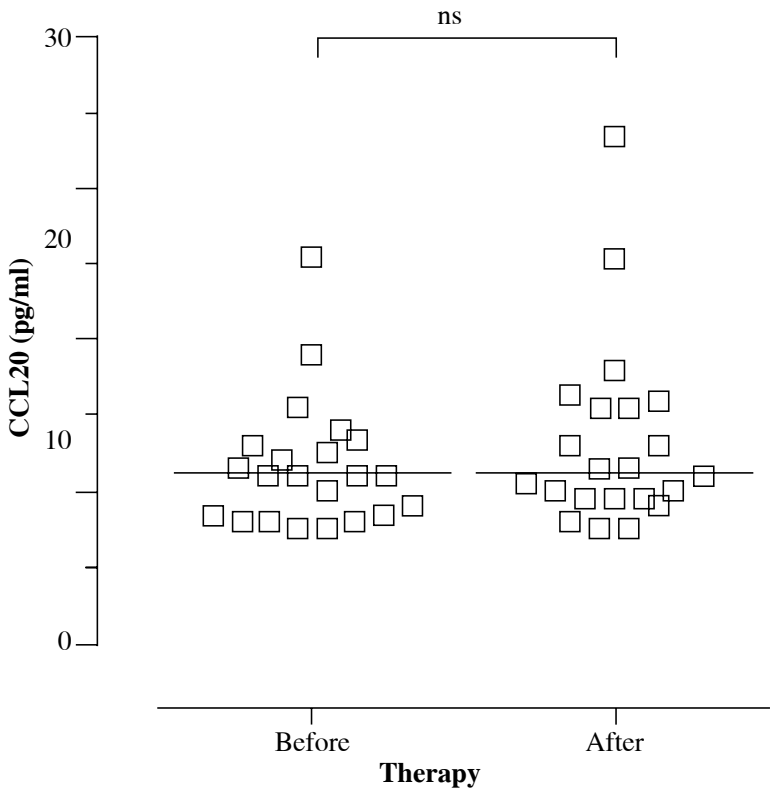

Fig. 2. Individual changes in serum CCL20 during anti-TNF- $\alpha$ therapy in rheumatoid arthritis patients

levels in some patients were undetectable despite the use of high sensitivity tests. An explanation may be that inflammation in these patients was not driven by the IL-17 pathway. In this respect, it has been observed that non-responders to anti-TNF- $\alpha$ produce high levels of IL-23/IL-17 and have a high frequency of circulating Th17 cells [12]. High baseline levels of IL-17 were also identified as a significant predictor of poor therapeutic response to anti-TNF treatment [13]. Because our group of patients consisted mainly of successful responders to anti-TNF- $\alpha$, the IL-23/ IL-17 pathway may have not been involved.

We also detected no effect of anti-TNF- $\alpha$ therapy on serum CCL20. Previous studies suggested that serum CCL20 in RA decreases in response to biologic treatment [17]. It has also been suggested that a polymorphism in CCR6, the gene encoding a receptor for CCL20 on Th17 cells, may determine the recruitment of Th17 cell to the joints, systemic IL-17, and RA susceptibility [35].

Despite lack of changes of serum levels of IL-17 and CCL20 in RA patients upon anti-TNF- $\alpha$ therapy in our study, it is possible that anti-TNF- $\alpha$ inhibitors could affect IL-17/CCL20 triggered signalling in effector cells [36]. This may result in an effect on disease activity [37]. It was suggested that the early responses to anti-TNF- $\alpha$ treatment in psoriasis may be due to decreased tissue responsiveness to IL-17 due to suppressed IL-17 receptor expression in keratinocytes [38]. It has also been shown that the increased IL-17 production in RA patients after anti-TNF treatment was accompanied by a decrease in Th17-specific CC-chemokine receptor expression, which might prevent homing of these potentially pro-inflammatory cells to the 
synovium [39]. It is therefore possible that despite the lack of changes of serum levels of IL-17 and CCL20, the downregulation of IL-17/CCL20 receptors affect IL-17/ CCL20 triggered signalling during treatment with TNF- $\alpha$ inhibitors.

Our study has some limitations, including a single-centre design and a small sample size. Additionally, patients had received a wide variety of medications.

\section{Conclusions}

Serum levels of IL-17A and CCL20 did not parallel changes in the clinical status and standard biochemical parameters that occur in patients undergoing anti-TNF- $\alpha$ treatment for RA. However, it is possible that anti-TNF- $\alpha$ inhibitors could affect IL-17/CCL20 triggered signalling in effector cells. Finally, the measurement of IL-17A and CCL20 in serum does not seem to provide additional information that would help to predict or monitor the response to biologic treatment in RA.

\section{Acknowledgements}

The research reported herein was funded by a Poznan University of Medical Sciences Grant for Young Researchers (no. 502-14-04412528-10592).

\section{The authors declare no conflict of interest.}

\section{References}

1. Furst DE, Emery P (2014): Rheumatoid arthritis pathophysiology: update on emerging cytokine and cytokine-associated cell targets. Rheumatology (Oxford) 53: 1560-1569.

2. Low AS, Symmons DP, Lunt M, et al. (2017): Relationship between exposure to tumour necrosis factor inhibitor therapy and incidence and severity of myocardial infarction in patients with rheumatoid arthritis. Ann Rheum Dis 76: 654-660.

3. Mewar D, Wilson AG (2011): Treatment of rheumatoid arthritis with tumour necrosis factor inhibitors. Br J Pharmacol 162: 785-791.

4. Eder P, Linke K, Witowski J (2016): Update on the mechanisms of action of antiTNF-alpha antibodies and their clinical implications in inflammatory bowel disease. Pol Arch Med Wewn 126: 772-780.

5. Ohshima S, Saeki Y, Mima T, et al. (1999): Long-term follow-up of the changes in circulating cytokines, soluble cytokine receptors, and white blood cell subset counts in patients with rheumatoid arthritis (RA) after monoclonal anti-TNF alpha antibody therapy. J Clin Immunol 19: 305-313.

6. Barrera P, Joosten LA, den Broeder AA, et al. (2001): Effects of treatment with a fully human anti-tumour necrosis factor alpha monoclonal antibody on the local and systemic homeostasis of interleukin 1 and TNFalpha in patients with rheumatoid arthritis. Ann Rheum Dis 60: 660-669.
7. Sadik CD, Kim ND, Alekseeva E, Luster AD (2011). IL-17RA signaling amplifies antibody-induced arthritis. PloS One 6: e26342.

8. Kugyelka R, Kohl Z, Olasz K, et al. (2016): Enigma of IL17 and Th17 Cells in Rheumatoid Arthritis and in Autoimmune Animal Models of Arthritis. Mediators Inflamm 2016: 6145810.

9. Lubberts E (2015): The IL-23-IL-17 axis in inflammatory arthritis. Nat Rev Rheumatol 11: 415-429.

10. Shahrara S, Pickens SR, Mandelin AM, 2nd, et al. (2010): IL-17-mediated monocyte migration occurs partially through CC chemokine ligand 2/monocyte chemoattractant protein-1 induction. J Immunol 184: 4479-4487.

11. Acosta-Rodriguez EV, Napolitani G, Lanzavecchia A, Sallusto F (2007): Interleukins 1beta and 6 but not transforming growth factor-beta are essential for the differentiation of interleukin 17-producing human T helper cells. Nat Immunol 8: 942-949.

12. Alzabin S, Abraham SM, Taher TE, et al. (2012): Incomplete response of inflammatory arthritis to TNFalpha blockade is associated with the Th17 pathway. Ann Rheum Dis 71: 17411748.

13. Chen DY, Chen YM, Chen HH, et al. (2011): Increasing levels of circulating Th17 cells and interleukin-17 in rheumatoid arthritis patients with an inadequate response to anti-TNF-alpha therapy. Arthritis Res Ther 13: R126.

14. Rosu A, Margaritescu C, Stepan A (2012): IL-17 patterns in synovium, serum and synovial fluid from treatment-naive, early rheumatoid arthritis patients. Rom J Morphol Embryol 53: 73-80.

15. Zhao PW, Jiang WG, Wang L, et al. (2014): Plasma levels of IL-37 and correlation with TNF-alpha, IL-17A, and disease activity during DMARD treatment of rheumatoid arthritis. PloS One 9: e95346.

16. Metawi SA, Abbas D, Kamal MM, Ibrahim MK (2011): Serum and synovial fluid levels of interleukin-17 in correlation with disease activity in patients with RA. Clin Rheumatol 30: 1201-1207.

17. Kawashiri SY, Kawakami A, Iwamoto N, et al. (2009): Proinflammatory cytokines synergistically enhance the production of chemokine ligand 20 (CCL20) from rheumatoid fibroblast-like synovial cells in vitro and serum CCL20 is reduced in vivo by biologic disease-modifying antirheumatic drugs. J Rheumatol 36: 2397-2402.

18. Kageyama Y, Kobayashi H, Kato N (2009): Infliximab treatment reduces the serum levels of interleukin-23 in patients with rheumatoid arthritis. Mod Rheumatol 19: 657-662.

19. Rasmussen TK, Andersen T, Hvid M, et al. (2010): Increased interleukin 21 (IL-21) and IL-23 are associated with increased disease activity and with radiographic status in patients with early rheumatoid arthritis. J Rheumatol 37: 2014-2020.

20. Walters HM, Pan N, Lehman TJ, et al. (2016): The impact of disease activity and tumour necrosis factor-alpha inhibitor therapy on cytokine levels in juvenile idiopathic arthritis. Clin Exp Immunol 184: 308-317.

21. Nirula A, Nilsen J, Klekotka P, et al. (2016): Effect of IL-17 receptor A blockade with brodalumab in inflammatory diseases. Rheumatology (Oxford) 55 (Suppl 2): ii43-ii55.

22. Kunwar S, Dahal K, Sharma S (2016): Anti-IL-17 therapy in treatment of rheumatoid arthritis: a systematic literature review and meta-analysis of randomized controlled trials. Rheumatol Int 36: 1065-1075. 
23. Raza K, Falciani F, Curnow SJ, et al. (2005): Early rheumatoid arthritis is characterized by a distinct and transient synovial fluid cytokine profile of $\mathrm{T}$ cell and stromal cell origin. Arthritis Res Ther 7: R784-795.

24. Aletaha D, Neogi T, Silman AJ, et al. (2010): 2010 rheumatoid arthritis classification criteria: an American College of Rheumatology/European League Against Rheumatism collaborative initiative. Ann Rheum Dis 69: 1580-1588.

25. Prevoo ML, van 't Hof MA, Kuper HH, et al. (1995): Modified disease activity scores that include twenty-eight-joint counts. Development and validation in a prospective longitudinal study of patients with rheumatoid arthritis. Arthritis Rheum 38: 44-48.

26. van Gestel AM, Prevoo ML, van 't Hof MA, et al. (1996): Development and validation of the European League Against Rheumatism response criteria for rheumatoid arthritis. Comparison with the preliminary American College of Rheumatology and the World Health Organization/International League Against Rheumatism Criteria. Arthritis Rheum 39: 34-40.

27. Izumi K, Kaneko Y, Hashizume M, et al. (2015): Baseline Serum Osteopontin Levels Predict the Clinical Effectiveness of Tocilizumab but Not Infliximab in Biologic-Naive Patients with Rheumatoid Arthritis: A Single-Center Prospective Study at 1 Year (the Keio First-Bio Cohort Study). PloS One 10: e0145468.

28. Avdeev AS, Novikov AA, Aleksandrova EN, et al. (2014): [The importance of cytokine profile characteristics for evaluating the therapeutic effectiveness of monoclonal antibodies against IL-6 receptors in patients with rheumatoid arthritis]. Klin Med (Mosk) 92: 28-34.

29. Yue C, You X, Zhao L, et al. (2010): The effects of adalimumab and methotrexate treatment on peripheral Th17 cells and IL-17/IL-6 secretion in rheumatoid arthritis patients. Rheumatol Int 30: 1553-1557.

30. Yamada H, Nakashima Y, Okazaki K, et al. (2008): Th1 but not Th17 cells predominate in the joints of patients with rheumatoid arthritis. Ann Rheum Dis 67: 1299-1304.

31. Cornelissen F, Asmawidjaja PS, Mus AM, et al. (2013): IL-23 dependent and independent stages of experimental arthritis: no clinical effect of therapeutic IL-23p19 inhibition in collagen-induced arthritis. PloS One 8: e57553.

32. Jain M, Attur M, Furer V, et al. (2015): Increased plasma IL$17 \mathrm{~F}$ levels in rheumatoid arthritis patients are responsive to methotrexate, anti-TNF, and T cell costimulatory modulation. Inflammation 38: 180-186.

33. Gaffen SL (2009): Structure and signalling in the IL-17 receptor family. Nat Rev Immunol 9: 556-567.

34. Koenders MI, Lubberts E, Oppers-Walgreen B, et al. (2005): Blocking of interleukin-17 during reactivation of experimental arthritis prevents joint inflammation and bone erosion by decreasing RANKL and interleukin-1. Am J Pathol 167: 141-149.

35. Kochi Y, Okada Y, Suzuki A, et al. (2010): A regulatory variant in CCR6 is associated with rheumatoid arthritis susceptibility. Nat Genet 42: 515-519.

36. Andersson KM, Cavallini NF, Hu D, et al. (2015): Pathogenic Transdifferentiation of Th17 Cells Contribute to Perpetuation of Rheumatoid Arthritis during Anti-TNF Treatment. Mol Med 21: 536-543.

37. Balato A, Scala E, Balato N, et al. (2017): Biologics that inhibit the Th17 pathway and related cytokines to treat inflammatory disorders. Expert Opin Biol Ther 17: 1363-1374.
38. Johnston A, Guzman AM, Swindell WR, et al. (2014): Early tissue responses in psoriasis to the antitumour necrosis factor-alpha biologic etanercept suggest reduced interleukin-17 receptor expression and signalling. Br J Dermatol 171: 97-107.

39. Aerts NE, De Knop KJ, Leysen J, et al. (2010): Increased IL-17 production by peripheral $\mathrm{T}$ helper cells after tumour necrosis factor blockade in rheumatoid arthritis is accompanied by inhibition of migration-associated chemokine receptor expression. Rheumatology (Oxford) 49: 2264-2272. 